\title{
INSTRUMENTAL PERFORATION OF THE OESOPHAGUS AND PERFORATED DUODENAL ULCER
}

\author{
BY \\ JAMES S. DAVIDSON \\ From the Bradford Royal Infirmary
}

(RECEIVED FOR PUBLICATION JULY 20, 1953)

Instrumental perforation of the oesophagus is a serious and, unfortunately, not a very rare accident. The occurrence in addition of perforation of a duodenal ulcer constitutes a situation which is rare, difficult to diagnose, and fraught with great danger to the patient.

Simultaneous perforation of multiple peptic ulcers has been described in several reports since that of Finney (1900). As peptic ulceration of the stomach and duodenum may be associated with peptic ulceration of the oesophagus, the synchronous perforation of these organs is a possibility. Apart from the type of case described by Yudin (1944) in which ingested corrosive causes destruction of the oesophagus and stomach, I can find no record of coexistent duodenal and oesophageal perforation.

In the following case coexistence of perforations of the oesophagus and duodenum is described.

\section{CASE Report}

A housewife, aged 33, was admitted to the Bradford Royal Infirmary on November 30, 1952. Two and a half months previously she had accidentally swallowed a teaspoonful of caustic soda in crystalline form in mistake for Epsom salt. On feeling an intense burning in her mouth, she drank a glass of milk and immediately vomited. Three days later she was able to swallow a little liquid for the first time since the accident. Thereafter she was able to swallow semisolids.

Two weeks before admission, oesophagoscopy and dilatation of a corrosive stricture had been carried out. Until then, apart from dysphagia, she had been without symptoms. On the following morning, she complained of pain between the shoulder blades on swallowing. Her condition subsequently deteriorated. She continued to have severe pain, especially after swallowing. Aften 10 days she began to vomit repeatedly. She developed diarrhoea. At that time also she began to cough up purulent sputum.

When first seen at the Bradford Royal Infirmary, she was complaining of severe pain in the interscapular region, and also of pain in the epigastrium and deep to the lower third of the sternum. Swallowing aggravated the pain and provoked cough productive of purulent sputum. She was toxic and dehydrated. Her temperature was $100^{\circ} \mathrm{F}$., pulse 120 per min., and respirations 32 per min. There were rigidity and tenderness in the epigastrium, dullness on percussion over the left lower lobe, and rales audible over the right lower lobe.

On the following morning, at 6 a.m., she developed still more severe pain in the epigastrium after drinking a little water. The epigastric rigidity was increased. Absence of liver dullness was noted.

A radiograph of the chest showed inflammatory changes in both lower lobes, and the presence of air under the diaphragm. The patient was given a dessertspoonful of viscous lipiodol to swallow. After two minutes she was radiographed sitting up in bed. The films showed lipiodol escaping from the oesophagus into the mediastinum (Fig. 1), and also lipiodol

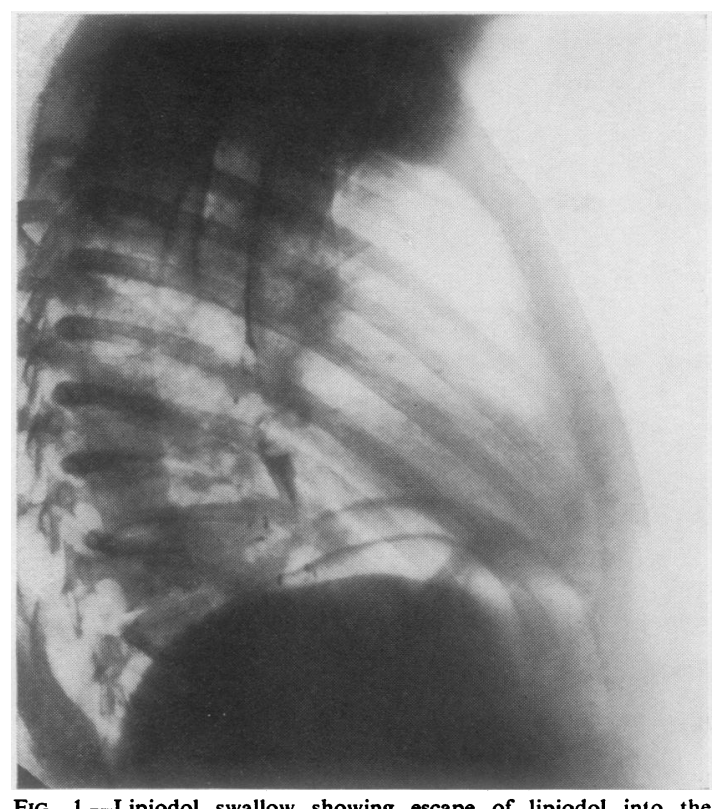

FIG. 1.-Lipiodol swallow showing escape of lipiodol into the mediastinum, gas under the diaphragm, and mediastinal abscess. 


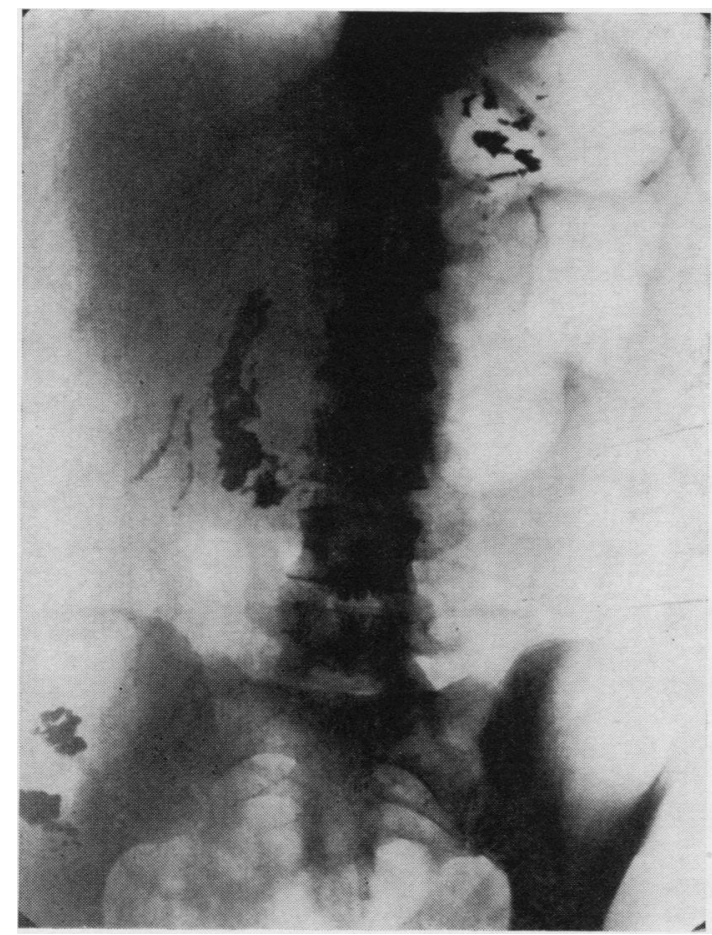

FIG. 2.-Radiograph two minutes after lipiodol swallow: lipiodol is escaping from the pyloric region and collecting in the right iliac fossa.

escaping into the peritoneal cavity from the bowel in the region of the pylorus and running down into the right iliac fossa (Fig. 2).

The diagnosis, therefore, was that of perforation of the oesophagus (with mediastinal abscess and oesophago-bronchial fistula), and a perforation in the duodenum or the pre-pyloric region of the stomach.

Laparotomy was performed on December 1, 1952. Thin, slightly turbid fluid was found in the peritoneal cavity. A perforation was found in the anterior wall of the first part of the duodenum. There was very little induration of the duodenal wall around the perforation. The perforation was closed by suture. A jejunostomy was performed.

The patient was then turned on her right side. After disarticulation at the costo-transverse joint, the tenth rib was removed medial to its angle. The mediastinum was approached extrapleurally. A large cavity containing pus and slough was entered. This cavity was drained.

Bronchoscopic aspiration of the bronchial tree was carried out.

The immediate post-operative course was difficult. The patient developed gross inflammatory changes in both lungs with atelectasis of both lower lobes.

Subsequent recovery was rapid. The patient raised sputum vigorously. Fluids were given intravenously for 24 hours. Thereafter she was allowed water by mouth. For some time a considerable amount of swallowed fluid escaped through the mediastinal drainage tube. Drip feeds were given through the jejunostomy tube till its removal five weeks after operation.

Dilatation of the corrosive stricture of the oesophagus $23 \mathrm{~cm}$. from the incisor teeth was carried out 17 days after operation and on two subsequent occasions at weekly intervals. The patient then began self-bouginage. She was discharged from hospital three weeks later with the jejunostomy opening healed and the oesophageal fistula closed. Self-bouginage was carried out on alternate days.

Her present condition is good. She passes a bougie without difficulty at weekly intervals. She eats normal food. Her weight, which was originally 12 st. and dropped to $8 \mathrm{st}$. $4 \mathrm{lb}$. after operation, is now $11 \mathrm{st} .3 \mathrm{lb}$. She has no cough or sputum. As before, she has no symptoms of indigestion. A barium swallow and meal shows the barium to pass without delay down the oesophagus which, however, is narrowed in its lower third. No ulcer crater can be seen in the duodenum.

\section{Discussion}

Comment may be made on two aspects of this case: the aetiology of the duodenal ulcer, and the manner in which diagnosis of a perforated ulcer was made.

As duodenal ulcer is common, and in $10 \%$ of those which perforate there are no previous symptoms, it may well be that the ulcer in this case was quite coincidental.

It is tempting to consider the perforated duodenal ulcer to be secondary to the oesophageal perforation and mediastinitis, either as a result of the severe infection and toxaemia or due to autonomic disturbance. Stimulation or blockage of the vagi in the lower thoracic region are well known profoundly to affect the physiology of the stomach and duodenum. Further, several papers have appeared, notably those of Mason and Pollard (1949) and of Harkins and Willard (1950), describing the adverse effects of dorso-lumbar sympathectomy on peptic ulcer. In the case described above, both the vagi and sympathetic nerves at the level of the lower third of the oesophagus passed through an area of intense inflammation and tissue destruction. It seems not unlikely that their function was disturbed. It is suggested, therefore, that the acute duodenal ulcer in this case may have been of neurogenic origin, possibly analogous to the peptic ulceration which has been described following dorso-lumbar sympathectomy.

The symptoms and signs of perforated duodenal ulcer were masked in this case by the already 
severe symptoms and signs of perforation of the oesophagus. Diagnosis of perforation of a duodenal ulcer was made possible by lipiodol swallow. The dangers of barium escaping into the peritoneal cavity are well known. In view of the frequent use of lipiodol in salpingography, it would appear that lipiodol in small quantity in the peritoneal cavity is relatively harmless. It is suggested that a lipiodol swallow, followed after a brief interval by a radiograph of the patient in bed, may on occasion be an aid to diagnosis in a case of suspected perforation of a gastric or duodenal ulcer. It is further suggested that visualization of the escape of lipiodol may give useful information when conservative treatment of a perforated peptic ulcer is being considered.

\section{SUMMARY}

A case of instrumental perforation of the oesophagus followed by perforation of an acute duodenal ulcer is described.

A possible aetiology of the duodenal ulcer is discussed.

Attention is drawn to the method of diagnosis of the perforated duodenal ulcer, and it is suggested that this method might be of use, especially in the non-operative management of perforation.

I wish to thank Mr. P. Harrison, M.S.R., for the $x$-ray photographs.

\section{REFERENCES}

Finney, J. T. (1900). Ann. Surg., 32, 1.

Harkins, F. A., and Willard, J. H.' (1950). Gastroenterology, 15, 530. Mason, S. C., and Pollard, H. M. (1949). Surg. Gynec. Obstet., 89, 271 Yudin, S. S. (1944). Ibid., 78, 561. 